\title{
Determinants of Medication Adherence in Nausea and Vomiting of Pregnancy
}

\author{
Israeli $\mathrm{I}^{1}$, Cohen $\mathrm{R}^{1}$, Berkovitch $\mathrm{M}^{1,2}$ and Koren $\mathrm{G}^{* 1,2,3}$
}

${ }^{1}$ Motherisk Israel, Clinical Pharmacology and Toxicology Unit, Assaf Harofeh Medical Center, Zerifin, Israel

${ }^{2}$ Sackler School of Medicine, Tel-Aviv University, Tel-Aviv, Israel

${ }^{3}$ Maccabi-Kahn Institute of Research and Innovation, Tel Aviv, Israel

${ }^{*}$ Corresponding author: Koren G, Motherisk Israel, Clinical Pharmacology and Toxicology Unit, Assaf Harofeh Medical Center, Zerifin, Israel, E-mail: Gidiup_2000@yahoo.com

Citation: Israeli I, Cohen R, Berkovitch M, Koren G (2018) Determinants of Medication Adherence in Nausea and Vomiting of Pregnancy. J Gynecol Res 4(2): 201. doi: 10.15744/2454-3284.4.201

Received Date: March 20, 2018 Accepted Date: September 04, 2018 Published Date: September 06, 2018

\begin{abstract}
Background: A major issue in adherence to medical treatment in nausea and vomiting of pregnancy (NVP) is mothers' fear of perceived teratogenic damage. The objective of this study was to identify predictors of adherence to medication treatment in NVP.

Methods: A prospective cohort study based on telephone interviews among women who experienced NVP and counseled by Motherisk Israel NVP Helpline, located in a teratology information service. The consultation was divided into pharmacological and non-pharmacological recommendations. Data on adherence to medications and pregnancy outcomes were collected during telephone follow up interviews which were carried out soon after the birth of the child.
\end{abstract}

Results: One hundred and eighty seven women were included in this analysis. The following determinants predicted improved medicinal adherence in multivariable analyses: low quality of sleep ( $\mathrm{OR}=2.72,95 \% \mathrm{CI} 1.12-6.56)$, medication treatment for pregnancy- related conditions (supporting pregnancy, prevention of complications, treatment of hypercoagulability) (OR=16.58, 95\% CI 1.64-167.65)), therapy with doxylamine /pyridoxine before the consultation ( $\mathrm{OR}=11.49,95 \% \mathrm{CI} .91-45.31)$, recommendation by the counselor for doxylamine/pyridoxine $(\mathrm{OR}=4.95,95 \% \mathrm{CI}$ 1.55-15.76) and recommendation for acid reducing medications $(\mathrm{OR}=3.91,95 \% \mathrm{CI} 1.185$ 12.92).

Conclusions: Favorable adherence to medicinal treatment of NVP is affected by the severity of symptoms and by success of previous therapy.

Keywords: Nausea and Vomiting of Pregnancy; Doxylamine/Pyridoxine; Adherence; Compliance

\section{Introduction}

Nausea and vomiting of pregnancy (NVP) is the most common medical condition during gestation with $50-90 \%$ of pregnant women being affected. Despite the suffering experienced by women and the extent of the symptoms, this condition receives little attention by the medical community [1]. Beyond the impairment of quality of life and poor physical and mental functioning, NVP bears considerable economic burden [2].

There is evidence that early management of NVP may prevent worsening of symptoms and their resultant complications. The most severe form of NVP, hyperemesis gravidarum, may occur due to ineffective treatment of NVP [3]. While for many women non medicinal management including dietary and lifestyle modifications may be sufficient, substantial numbers of women with moderate and severe symptoms require pharmacological treatment [4].Selecting effective pharmacological treatment for NVP symptoms which is safe to the fetus is a major concern for pregnant women and their health care providers [5].This issue is particularly sensitive in light of the overlap between the time of onset of NVP (early pregnancy) and the period of organogenesis, when drugs may exert teratogenic effects [4].

According to drug registries of Clalit (the largest health medical organization in Israel), the rates of pregnant women consuming metoclopramide, H2 Blockers and PPIs for NVP in the Southern district in Israel in 2009 were $7.1 \%, 2.3 \%$, and 2.2\%, respectively. This suggests that only a small proportion of women with NVP are treated pharmacologically [6].

Non medicinal management of NVP is often perceived as more favorable by pregnant women who feel it is harmless [1]. Ironically, these products do not require a proof of efficacy and safety and are not subject to the strict regulation of medicinal drugs. 
The perception of teratogenic risk is a major determinant in the common non-adherence to medicinal treatment among pregnant women, and this has the potential to impact negatively treatment outcomes. Pregnant women tend to overestimate the potential risks of using medications during pregnancy, leading them sometime to avoid even lifesaving therapy [7].

The objective in this study was to identify determinants of adherence to medications in pregnant women with NVP to improve the health and quality of life of pregnant women suffering from this common medical condition.

\section{Methods}

\section{Study Design}

This was a prospective cohort study of 193 pregnant women experiencing NVP who sought counseling at the Motherisk Israel Helpline for NVP at a teratogen information service at Assaf Harofeh Medical Center. The callers received counseling and support from a pharmacist specialized in the field of NVP. Providing comprehensive counseling on the different medications proven to be effective and safe in pregnancy is aimed to reduce misperceptions of teratogenic risk, allowing women to be treated optimally [8].

The first encounter was when the pregnant woman called the Motherisk center for advice on nausea and vomiting during pregnancy. During the consultation, the pharmacist recorded demographic details, history of previous pregnancies, course of the present pregnancy, medical history, medications and information about nausea and / or vomiting symptoms. The consultation the women received was divided into non-pharmacological and pharmacological aspects.

The follow up telephone interview was conducted mostly within 5 months after the birth of the child. During the interview, a structured questionnaire was used to fill in details of the woman's degree of adherence to the medicinal recommendations given to her. The response was recorded dichotomously as "yes", or "no" (Table 3). Participants were defined as "lost to follow up" after having made five unanswered telephone calls at different times during the day.

The study was approved by the institutional ethics committee of Assaf Harofeh Medical Center (0246-15-ASF).

\section{Study Population}

The study population included pregnant women with NVP who called the NVP support helpline, located in the Clinical Pharmacology Unit at Assaf Harofeh Medical Center, from March 2014 to September 2015.

Exclusion criteria were refusal to participate in the study, women with NVP who had twins, or partial response to follow-up questionnaire.

\section{Variables}

The dependent variable was the rate of adherence to the original treatment recommendations given to the woman during the counseling session in Motherisk. Adherence was defined as following the advice given by the pharmacist. The independent variables included maternal age, gestational age at referral, mother's background diseases, level of education (under 12 years of schooling, academic degree), occupation (unemployed, student, employed, self-employed), number of days of absence from work due to NVP, gastrointestinal disorders (heartburn, reflux, abdominal pain, indigestion, infection with Helicobacter pylori, bloating, constipation, excessive saliva), smoking and alcohol use during pregnancy, number of pregnancies and child's age at follow-up. The severity of NVP symptoms at the time of counseling was quantified by the validated PUQE (pregnancy-unique quantification of emesis) score ranging from 3 (no symptoms) to 15 (the most severe symptoms) [9].

\section{Statistical Analysis}

Categorical variables were described using frequency and percentage. Sequential variables were examined for normal distribution using a histogram and the Kolmogorov-Smirnov test. Sequential variables that were normally distributed were described using mean and standard deviation and non-normally distributed variables were described using median and quarterly interval.

A univariate analysis of sequential predictors of medicinal adherence was conducted using t-test or the Mann Whitney test when appropriate. An analysis of categorical variables was conducted using a chi-squared test or Fisher's exact test. Multivariable analysis was conducted using logistic regression. Variables were included in the logistic regression if they had significance of $\mathrm{P}<0.1$ in the univariate analysis, and also variables that were defined as clinically important. The logistic regression consisted of 3 block stages. The first block included: mother's age, gestational week in which the woman contacted the NVP helpline and the severity of nausea during pregnancy as measured by the PUQE score. The second and third blocks were performed using the Backward (Wald) method, where the condition for expenditure was $\mathrm{P}<0.1$. The second block included variables related to the characteristics of the mother. The third block included medicinal treatment. The quality of adjustment of the logistic regression model was examined using the Hosmer-Lemeshow test. All tests were two-sided. The statistical analysis was performed by using SPSS statistics software, version 24 . 


\section{Results}

A telephone consultation was performed in 288 women who contacted the NVP helpline. Of these, 51 women did not respond to the telephone call, and 44 answered but refused to participate in the study, hence 193 women participated. In addition, 6 women agreed to participate in the study, but were excluded from analysis due to partial or unclear documentation of the details of the referral and due to a case of the birth of twins. Of 193 women, 187 women were included in the final study group. The 187 women who participated in the study were not different in any characteristic when compared to women who did not participate in the study.

\section{Background Characteristics}

The mean age of the women was $31.9 \pm 5.7$. The median gestational age at the women's referral date was 8 weeks (IQR 7-10). The most common background diseases were migraines (15.5\%) and psychiatric disorders (15.0\%), most of whom suffered from anxiety disorders and depression. In addition, most of the women had higher education, and only $21.5 \%$ had 12 years of schooling or less. Most of the women were employed. Due to NVP women reported at the time of referral a median number of 2 days of absence from work. $92.1 \%$ of the women reported that, apart from nausea and vomiting, they also suffered from other gastrointestinal symptoms. Overall, low rates of smoking $(2.1 \%$ of women) were reported, and there were no cases of alcohol use. The median number of pregnancies of the study population was 2 , and the median age of the children at the time of the follow-up was 4 months (Table 1 and 2).

\begin{tabular}{|c|c|c|}
\hline \multicolumn{2}{|c|}{ Variable } & $\begin{array}{l}\text { Study group } \\
\quad(\mathrm{n}=187)\end{array}$ \\
\hline \multicolumn{2}{|c|}{ Maternal age at first contact, mean \pm SD, y } & $31.9 \pm 5.7$ \\
\hline \multicolumn{2}{|c|}{ Gestational age at first contact, median(IQR), wk } & $8.0(7.0-10.0)$ \\
\hline \multicolumn{3}{|c|}{ Chronic maternal illness, $\mathrm{n}(\%)$} \\
\hline \multicolumn{2}{|c|}{ Psychatric Disorders } & $28(15.0)$ \\
\hline \multicolumn{2}{|c|}{ Migraines } & $29(15.5)$ \\
\hline \multirow{3}{*}{$\begin{array}{l}\text { Maternal education, } \\
\mathrm{n}(\%)\end{array}$} & $<=12$ years & $34(21.5)$ \\
\hline & University & $103(65.2)$ \\
\hline & Post Graduate Training & $21(13.3)$ \\
\hline \multirow{4}{*}{$\begin{array}{l}\text { Maternal occupation, } \\
\mathrm{n}(\%)\end{array}$} & Unemployed & $29(15.7)$ \\
\hline & Student & $8(4.3)$ \\
\hline & Employed & $145(78.8)$ \\
\hline & Self employed & $2(1.1)$ \\
\hline \multicolumn{2}{|c|}{$\begin{array}{l}\text { Time lost from work before first contact, } \\
\text { median(IQR), dys }\end{array}$} & $2.0(0.0-7.8)$ \\
\hline \multicolumn{3}{|c|}{ GI Conditions at first contact, $\mathrm{n}(\%)$} \\
\hline \multicolumn{2}{|c|}{ Heartburn } & $81(44.5)$ \\
\hline \multicolumn{2}{|c|}{ Acid reflux } & $72(41.1)$ \\
\hline \multicolumn{2}{|c|}{ Stomach pain } & $99(54.1)$ \\
\hline \multicolumn{2}{|c|}{ Indigestion } & $13(8.4)$ \\
\hline \multicolumn{2}{|c|}{ H. Pylori } & $3(4.3)$ \\
\hline \multicolumn{2}{|c|}{ Gas/Bloating } & $80(44.4)$ \\
\hline \multicolumn{2}{|c|}{ Constipation } & $63(34.8)$ \\
\hline \multicolumn{2}{|c|}{ Excessive saliva } & $69(39.9)$ \\
\hline \multicolumn{2}{|c|}{ Any GI condition } & $164(92.1)$ \\
\hline \multicolumn{2}{|c|}{ Alcohol consumption at first contact, n(\%) } & $0(0)$ \\
\hline \multicolumn{2}{|c|}{ Tobacco consumption at first contact, n(\%) } & $4(2.1)$ \\
\hline \multicolumn{2}{|c|}{ Number of pregnancies, median(IQR) } & $2.0(2.0-4.0)$ \\
\hline \multicolumn{2}{|c|}{ Age at FU, median (IQR), months } & $4.0(2.5-9.0)$ \\
\hline $\begin{array}{l}\text { SD-Standard deviat } \\
\text { IQR-Interquartile } \\
\text { Table 1: Display of }\end{array}$ & background cha & ( \\
\hline
\end{tabular}




\section{Medicinal Adherence}

\begin{tabular}{|c|c|}
\hline Variable & Study group $(\mathbf{n}=\mathbf{1 8 7})$ \\
\hline $\begin{array}{c}\text { Any medication or dietary } \\
\text { supplement, } \mathrm{n}(\%)\end{array}$ & $184(98.4)$ \\
\hline Metoclopramide, $\mathrm{n}(\%)$ & $63(33.7)$ \\
\hline Diclectin/Doxylamine, $\mathrm{n}(\%)$ & $91(48.7)$ \\
\hline Dimenhydrinate, $\mathrm{n}(\%)$ & $15(8.0)$ \\
\hline Ondansetron, $\mathrm{n}(\%)$ & $50(26.7)$ \\
\hline Ginger, $\mathrm{n}(\%)$ & $37(19.8)$ \\
\hline Vitamin B6, $\mathrm{n}(\%)$ & $34(18.2)$ \\
\hline
\end{tabular}

Table 2: Medications and Dietary Supplements for the Treatment of NVP $98.4 \%$ of women took some medication or dietary supplement to relieve the NVP. About half (48.7\%) of women took diclectin (doxylamine/ pyridoxine), or doxylamine alone during pregnancy, followed by metoclopramide and ondansetron.

Table 3 summarizes recommendations given by the NVP helpline, the rates of adherence to recommendations and the rates of exposure to treatments recommended by the NVP helpline prior to referral. With regard to prescription medications, a quarter of women $(28.9 \%)$ were treated with metoclopramide prior to referral to the NVP helpline. Furthermore, most of the women $(70.1 \%)$ who contacted the NVP helpline received a recommendation to take the doxylamine/pyridoxine combination. In addition, more than half of the women who received a recommendation for metoclopramide, doxylamine/pyridoxine or omeprazole adhered to the treatment $(55.2 \%, 51.9 \%$, and $63.2 \%$, respectively). In terms of adherence to over-the-counter medications, high adherence was observed to recommendations to doxylamine or antacids ( $87.5 \%$ and $70.0 \%$, respectively). Most of the women (97.9\%) received dietary recommendations and $81.2 \%$ adhered to thesm recommendations. $55.1 \%$ of the women who contacted the NVP helpline received recommendations for lifestyle modifications such as rest, and $84.6 \%$ of the women adhered to them.

\begin{tabular}{|c|c|c|c|c|}
\hline & & $\begin{array}{c}\text { Before consultation } \\
{[\mathbf{n}(\%)]}\end{array}$ & $\begin{array}{l}\text { Recommendations at } \\
\text { consultation }[\mathrm{n}(\%)]\end{array}$ & $\begin{array}{c}\text { Adherence to } \\
\text { recommendations } \\
{[\mathbf{n}(\%)]}\end{array}$ \\
\hline \multirow{9}{*}{ Prescription medicines } & Metoclopramide & $54(28.9)$ & $29(15.5)$ & $16(55.2)$ \\
\hline & Doxylamine/vitB6 & $36(19.3)$ & $131(70.1)$ & $68(51.9)$ \\
\hline & Ondansetron & $50(26.7)$ & $7(3.7)$ & 3 (42.9) \\
\hline & Promethazine & $1(0.5)$ & $0(0.0)$ & $0(0.0)$ \\
\hline & Omeprazole & $5(2.7)$ & $38(20.3)$ & $24(63.2)$ \\
\hline & Famotidine & $4(2.1)$ & $20(10.7)$ & $7(36.8)$ \\
\hline & Ranitidine & $5(2.7)$ & $0(0.0)$ & $0(0.0)$ \\
\hline & Lansoprazole & $1(0.5)$ & $0(0.0)$ & $0(0.0)$ \\
\hline & Prednisone & $0(0.0)$ & $1(0.5)$ & $1(100)$ \\
\hline \multirow{6}{*}{$\begin{array}{l}\text { Over the counter } \\
\text { medications }\end{array}$} & Dimenhydrinate & $3(1.6)$ & $54(28.9)$ & $13(24.1)$ \\
\hline & Meclizine & $1(0.5)$ & $0(0.0)$ & $0(0.0)$ \\
\hline & Doxylamine & $8(4.3)$ & $8(4.3)$ & $7(87.5)$ \\
\hline & Antacid & $3(1.6)$ & $41(21.9)$ & $28(70.0)$ \\
\hline & Anti-constipation & $6(3.2)$ & $23(12.3)$ & $1(4.3)$ \\
\hline & Simethicone & $0(0.0)$ & $4(2.1)$ & $0(0.0)$ \\
\hline \multirow{2}{*}{ Dietary supplements } & Ginger & $35(18.7)$ & $3(1.6)$ & $3(100.0)$ \\
\hline & Vitamin B6 & $31(16.6)$ & $17(9.1)$ & $4(23.5)$ \\
\hline \multirow{5}{*}{$\begin{array}{l}\text { Other } \\
\text { recommendations }\end{array}$} & Nutrition & $0(0.0)$ & $183(97.9)$ & $147(81.2)$ \\
\hline & Lifestyle & $0(0.0)$ & $103(55.1)$ & $88(84.6)$ \\
\hline & Acupuncture & $0(0.0)$ & $39(20.9)$ & $12(30.8)$ \\
\hline & P6 Acupressure & $0(0.0)$ & $55(29.4)$ & $11(20.0)$ \\
\hline & Electrolytes Sol & $0(0.0)$ & $24(12.8)$ & $2(8.3)$ \\
\hline
\end{tabular}

Table 3: Recommendations, Adherence to recommendations and Exposure to various treatments prior to referral 
Among the 187 participants the rate of adherence to any recommendation was $96.8 \%$. The adherence rate for any recommendation that included medications was $65.1 \%$ of 172 .

- PUQE score is the validated Pregnancy-Unique Quantification of Emesis score, ranged from 3 (no symptoms) to 15 (the most severe symptoms)[9].

Table 4 presents the 172 pregnant women who received a medicinal recommendation. Among those who adhered, there was a higher number of days of absence from work, higher rate of medicinal treatment in relation to pregnancy (support for pregnancy, treatment of hypercoagulability or prevention of pregnancy complications) before referral to the NVP helpline, more heartburn symptoms at the time of referral, and more referrals to emergency departments or hospitalization due to NVP before referral. There were also more referrals to community emergency medical center due to NVP after referral to the NVP helpline, taking diclectin/ doxylamine or ondansetron or medications to relieve heartburn symptoms before referral to NVP helpline, and receiving recommendation for treatment with diclectin/doxylamine or medications to relieve heartburn symptoms or electrolyte solutions at the time of referral. Also, those who adhered had a higher PUQE score indicating a higher severity of NVP, quality of sleep was poorer and the impairment of the quality of life was more significant. No difference was found between those who adhered and those who didn't in age of the women, the number of pregnancies and the frequency of vomiting during pregnancy.

\begin{tabular}{|c|c|c|c|c|}
\hline & & \multicolumn{2}{|c|}{ Medication adherence } & \multirow{2}{*}{ p Value } \\
\hline & & no & Yes & \\
\hline \multicolumn{2}{|c|}{ Maternal age at first contact, mean $\pm \mathrm{SD}, \mathrm{y}$} & $31.1(5.2)$ & $32.1(5.9)$ & 0.294 \\
\hline \multicolumn{2}{|c|}{ Gestational age at first contact, median(IQR), wk } & $8.0(7.0-10.0)$ & $8.5(7.0-10.0)$ & 0.326 \\
\hline \multirow{3}{*}{$\begin{array}{l}\text { Severity of NVP at first contact, } \\
\qquad \mathrm{n}(\%)\end{array}$} & Mild & $4(8.3 \%)$ & $1(1.0 \%)$ & \multirow{3}{*}{0.096} \\
\hline & Moderate & $8(16.7 \%)$ & $15(15.5 \%)$ & \\
\hline & Severe & $36(75.0 \%)$ & $80(82.5 \%)$ & \\
\hline \multicolumn{2}{|c|}{ Severity of nausea during pregnancy, median(IQR) } & $8.0(7.0-10.0)$ & $9.0(8.0-10.0)$ & 0.056 \\
\hline \multirow{2}{*}{$\begin{array}{l}\text { Frequency of vomiting during } \\
\text { pregnancy, } \mathrm{n}(\%)\end{array}$} & All day & $55(93.2 \%)$ & $116(96.7 \%)$ & \multirow{2}{*}{0.038} \\
\hline & Once a day & $4(6.8 \%)$ & $4(3.3 \%)$ & \\
\hline \multicolumn{2}{|c|}{$\begin{array}{l}\text { Healthcare provider consultation prior to first contact, } \\
\qquad \mathrm{n}(\%)\end{array}$} & $47(78.3 \%)$ & $100(89.3 \%)$ & 0.052 \\
\hline \multirow{3}{*}{ Maternal education, $\mathrm{n}(\%)$} & $<=12$ years & $18(34.0 \%)$ & $16(17.2 \%)$ & 0.093 \\
\hline & University & $28(52.8 \%)$ & $65(69.9 \%)$ & \\
\hline & $\begin{array}{l}\text { Post Graduate } \\
\text { Training }\end{array}$ & $7(13.2 \%)$ & $12(12.9 \%)$ & \\
\hline \multirow{4}{*}{ Maternal occupation, n(\%) } & Unemployed & $14(23.7 \%)$ & $13(11.8 \%)$ & 0.076 \\
\hline & Student & $3(5.1 \%)$ & $5(4.5 \%)$ & \\
\hline & Employed & $41(69.5 \%)$ & $92(83.6 \%)$ & \\
\hline & Self Employed & $1(1.7 \%)$ & $0(0.0 \%)$ & \\
\hline \multicolumn{2}{|c|}{$\begin{array}{l}\text { Time lost from work before first contact, median(IQR), } \\
\text { dys }\end{array}$} & $1.0(0.0-3.8)$ & $2.0(0.0-11.0)$ & 0.023 \\
\hline \multicolumn{2}{|c|}{ Pregnancy order, median (IQR) } & $2.0(2.0-4.0)$ & $3.0(2.0-4.0)$ & 0.52 \\
\hline \multirow{3}{*}{$\begin{array}{l}\text { Highest severity of NVP in } \\
\text { previous pregnancies, } \mathrm{n}(\%)\end{array}$} & Mild & $4(17.4 \%)$ & $5(8.1 \%)$ & 0.098 \\
\hline & Moderate & $8(34.8 \%)$ & $12(19.4 \%)$ & \\
\hline & Severe & $11(47.8 \%)$ & $45(72.6 \%)$ & \\
\hline \multicolumn{2}{|c|}{$\begin{array}{l}\mathrm{PUQE}^{*} \text { Score-nausea or sick at stomach duration in } \\
\text { the last } 24 \mathrm{hr} \text {, median (IQR) }\end{array}$} & $5.0(5.0-5.0)$ & $5.0(5.0-5.0)$ & 0.046 \\
\hline \multicolumn{2}{|c|}{$\begin{array}{l}\text { PUQE Score-vomited or thrown up number of times } \\
\text { in the last } 24 \mathrm{hr} \text {, median (IQR) }\end{array}$} & $1.5(1.0-2.0)$ & $2.0(1.0-3.0)$ & 0.01 \\
\hline \multicolumn{2}{|c|}{ PUQE score, median (IQR) } & $8.0(7.0-10.0)$ & $9.0(8.0-11.0)$ & 0.023 \\
\hline \multicolumn{2}{|c|}{ Sleep duration before first contact, median (IQR), hrs } & $8.0(7.0-10.0)$ & $8.0(7.0-9.0)$ & 0.08 \\
\hline \multicolumn{2}{|c|}{ Low quality sleep, $\mathrm{n}(\%)$} & $31(51.7 \%)$ & $73(68.2 \%)$ & 0.034 \\
\hline \multicolumn{2}{|c|}{$\begin{array}{l}\text { Low well-being rate at first contact because of } \\
\text { weakness, } \mathrm{n}(\%)\end{array}$} & $11(21.2 \%)$ & $36(36.7 \%)$ & 0.05 \\
\hline \multicolumn{2}{|c|}{ Reduced quality of life due to NVP, median(IQR) } & $8.0(6.0-10.0)$ & $9.0(7.0-10.0)$ & 0.014 \\
\hline \multicolumn{2}{|c|}{ Medicinal treatment for anxiety, $\mathrm{n}(\%)$} & $1(1.7 \%)$ & $11(9.7 \%)$ & 0.059 \\
\hline \multicolumn{2}{|c|}{$\begin{array}{l}\text { Medicinal treatment for pregnancy support or } \\
\text { prevention of pregnancy complications, } n(\%)\end{array}$} & $1(1.7 \%)$ & $16(14.2 \%)$ & 0.009 \\
\hline
\end{tabular}




\begin{tabular}{|c|c|c|c|}
\hline & \multicolumn{2}{|c|}{ Medication adherence } & \multirow{2}{*}{ p Value } \\
\hline & no & Yes & \\
\hline Heartburn symptoms at first contact, n(\%) & $19(32.8 \%)$ & $59(54.1 \%)$ & 0.008 \\
\hline ER admission prior to first contact due to NVP, n(\%) & $5(8.3 \%)$ & $23(20.5 \%)$ & 0.039 \\
\hline Hospitalization prior to first contact due to NVP, $\mathrm{n}(\%)$ & $1(1.7 \%)$ & $12(10.7 \%)$ & 0.035 \\
\hline $\begin{array}{l}\text { Emergency medical center admission after first contact } \\
\text { due to NVP, } \mathrm{n}(\%)\end{array}$ & $12(20.7 \%)$ & $49(44.1 \%)$ & 0.003 \\
\hline Diclectin/Doxylamine before consultation, $\mathrm{n}(\%)$ & $3(5.0 \%)$ & $37(32.7 \%)$ & $<0.001$ \\
\hline Zofran before consultation, $\mathrm{n}(\%)$ & $10(16.7 \%)$ & $35(31.3 \%)$ & 0.038 \\
\hline Heartburn medications before consultation, $\mathrm{n}(\%)$ & $0(0.0 \%)$ & $17(15.2 \%)$ & 0.001 \\
\hline Ginger before consultation, $\mathrm{n}(\%)$ & $7(11.7 \%)$ & $25(22.3 \%)$ & 0.087 \\
\hline Recommendation of Zofran at first contact, $\mathrm{n}(\%)$ & $0(0.0 \%)$ & $7(6.3 \%)$ & 0.098 \\
\hline $\begin{array}{l}\text { Recommendation of heartburn medications at first } \\
\text { contact, } \mathrm{n}(\%)\end{array}$ & $23(38.3 \%)$ & $74(65.5 \%)$ & 0.001 \\
\hline $\begin{array}{l}\text { Recommendation of Diclectin/Doxylamine at first } \\
\text { contact, } \mathrm{n}(\%)\end{array}$ & $42(70.0 \%)$ & $94(83.2 \%)$ & 0.044 \\
\hline $\begin{array}{l}\text { Recommendation of electrolyte solution at first } \\
\text { contact, } \mathrm{n}(\%)\end{array}$ & $4(6.7 \%)$ & $20(17.9 \%)$ & 0.044 \\
\hline
\end{tabular}

$S D$ - Standard deviation, IQR-Interquartile Range, $p$-Values in bold indicate statistical significance $(p<0.05)$

Table 4: A univariate analysis of predictors to medicinal adherence

As shown in Table 5, the factors that predicted favorable medicinal adherence in multivariable analysis included: Poor quality of sleep $(\mathrm{OR}=2.72,95 \% \mathrm{CI}(1.12-6.56))$, taking diclectin or doxylamine before referral to the NVP helpline $(\mathrm{OR}=11.49,95 \%$ CI (2.91-45.31), receiving recommendation for treatment of heartburn symptoms during referral $(\mathrm{OR}=3.91,95 \% \mathrm{CI}(1.18$ 12.92), receiving recommendation for treatment with diclectin or doxylamine during referral $(\mathrm{OR}=4.95$, 95\% CI (1.55-15.76), taking medication in relation to pregnancy (support for pregnancy, treatment of hypercoagulability or prevention of pregnancy complications) before referral to the NVP helpline (OR = 16.58, 95\% CI (1.64-167.65).

\begin{tabular}{|c|c|c|c|c|}
\hline & \multirow{2}{*}{ OR } & \multicolumn{2}{|c|}{ 95\%CI for OR } & \multirow[t]{2}{*}{ p Value } \\
\hline & & Lower & Upper & \\
\hline Maternal age at first contact & 0.992 & 0.917 & 1.073 & 0.834 \\
\hline Gestational age at first contact & 0.943 & 0.826 & 1.078 & 0.391 \\
\hline Severity of nausea during pregnancy & 0.96 & 0.678 & 1.357 & 0.815 \\
\hline Low quality sleep & 2.717 & 1.125 & 6.563 & 0.026 \\
\hline Reduced quality of life due to NVP & 1.173 & 0.914 & 1.505 & 0.209 \\
\hline Heartburn symptoms at first contact & 1.102 & 0.333 & 3.654 & 0.873 \\
\hline $\begin{array}{l}\text { Diclectin/Doxylamine before } \\
\text { consultation }\end{array}$ & 11.491 & 2.914 & 45.31 & $<0.001$ \\
\hline $\begin{array}{l}\text { Recommendation of heartburn } \\
\text { medications at first contact }\end{array}$ & 3.914 & 1.185 & 12.925 & 0.025 \\
\hline $\begin{array}{l}\text { Recommendation of Diclectin/ } \\
\text { Doxylamine at first contact }\end{array}$ & 4.948 & 1.553 & 15.761 & 0.007 \\
\hline $\begin{array}{l}\text { Medicinal treatment for pregnancy } \\
\text { support or prevention of pregnancy } \\
\text { complications }\end{array}$ & 16.581 & 1.64 & 167.648 & 0.017 \\
\hline Medicinal treatment for anxiety & 7.14 & 0.734 & 69.434 & 0.09 \\
\hline
\end{tabular}

Table 5: A multivariate analysis of predictors to medicinal adherence

\section{Discussion}

Up to $90 \%$ of pregnant women suffer from NVP. In extreme cases, some women decide to undergo abortions to relief their severe symptoms. Early treatment can prevent complications due to worsening of symptoms. While numerous studies have shown that there are effective and safe medications to treat NVP symptoms, fears of congenital malformations lead many women to refrain from effective treatment.

The study included a cohort of 187 women with NVP, who contacted the NVP helpline. Our study focused on examination of the adherence to medicinal treatment, and understanding predictors of non-adherence. This issue is of great importance to ensure optimal treatment, and there are limited published data addressing it. 
Similar to a previous study, women who contacted an NVP helpline in Canada, are typically in their 30s, educated, employed, married and in their second pregnancy [10]. The referral to the center took place in weeks when the severity of nausea and vomiting typically reaches its peak. Among the studied women there was a high incidence of medical conditions that affect the quality of life, such as anxiety and depression, which urged them to seek help and support from other sources.

Adherence to medications is defined as the degree to which a patient takes prescribed drugs according to the instructions given to him/her by the medical staff [11]. Understanding factors affecting medicinal adherence is clinically important, as low adherence reduces effectiveness, leading to worsening of symptoms, prolonged hospitalization, need for more aggressive treatment, as well as greater costs to the health system. Among pregnant women, the issue of adherence requires even greater attention because pregnant women tend to overestimate the potential teratogenic risks, even for medications that have been shown to be safe for use in pregnancy. Indeed, the most common reason observed in our study for non-adherence with medication was the fear of harm to the fetus.

We found that poor quality of sleep, taking diclectin or doxylamine before referral to the NVP helpline, receiving recommendation for treatment of heartburn symptoms during referral, receiving recommendation for treatment with diclectin or doxylamine during referral, taking medication in relation to pregnancy complications (support for pregnancy, treatment of hypercoagulability or prevention of pregnancy complications) before referral to NVP helpline, were all factors that predicted favorable medication adherence.

Characteristics that impair daily functioning were found to be associated with higher adherence to treatment [12].This explains that poor sleep quality is a factor that predicts adherence with medicinal treatment.

Higher adherence rates were observed more frequently in patients with acute and symptomatic medical conditions [12,13].This can explain the fact that women who were recommended for treatment with heartburn medication at the time of referral to NVP helpline adhered favorably to the medicinal recommendations given to them.

Pregnant women may be motivated to take their medications for the well-being of their babies, especially when there is awareness of the potential negative consequences for the fetus following the avoidance of important medications that ensure the continuation of a healthy pregnancy [14].Indeed, this was reflected in adhering to medication in connection with pregnancy support, such as treatment of hypercoagulability or prevention of complications of pregnancy prior to the referral predicted adherence to medicinal treatment.

Diclectin is a delayed release tablet containing a combination of doxylamine and pyridoxine and constitute first line treatment in women suffering from NVP in Israel. Pregnant women taking diclectin typically experience improvement in NV P symptoms, as well as improved quality of life $[15,16]$. In this cohort of women the referral to the NVP helpline was made during the peak weeks of nausea and vomiting, and they exhibited mostly moderate and severe symptoms, as measured by the validated PUQE score [17]. The patient's belief in the benefit of the recommended medicinal treatment is related to medication adherence [11]. Such belief may be the result of previous successful experience with diclectin or doxylamine before referring for counseling and support by the helpline.

Diclectin is the only medication registered by the Israeli Ministry of Health specifically for the treatment of NVP. This provides security for both the medical team and the pregnant patients regarding the proven efficacy and safety of the preparation. Doxylamine is also available as over the counter medication, making it easier for pregnant women to purchase it [1].Hence, receiving a recommendation for treatment with diclectin or doxylamine during referral to the NVP helpline increases the likelihood of medication adherence.

\section{Strengths and Limitations of the Study}

The study was a prospective cohort in which most women who sought counseling were highly motivated to achieve relief from NVP symptoms. Therefore, there is certainty regarding the accuracy of the personal information provided in real time by the women. In addition, in light of the consultation and support call that is sometimes up to one hour long, the women had the patience and willingness to answer the comprehensive post-natal follow-up questionnaire. As a result, it is likely that the quality of information obtained through the questionnaires is high.

This study addresses aspects which have been dealt with only sparsely in previous research, such as the impact of counseling on women with NVP. Previous studies have shown that many women with NVP feel isolated and neglected as their symptoms are not taken seriously by health professionals [8].

The information in this study was collected from pregnancies in which a referral to a counseling and support helpline was made due to moderate-to severe symptoms. Moreover, typical of other support services, the women tended to be of higher education levels than in the general population. This group may not be generalizable for women with less severe NVP; however, it does reflect those in greater need for support. 
The information collected during the completion of the follow-up questionnaire was based on women's reports and may be subject to recall bias which may be affected by the interval between therapy and followup. However, the interviews were conducted at an early postnatal age, mostly within 5 months of birth. It is possible that women would under report lifestyle issues such as smoking and alcohol consumption, but these were not a focus in the present study.

\section{Conclusion}

In conclusion, understanding determinants of medicinal adherence in women with NVP may inform clinical practice in identifying patients who are at risk of low adherence, resulting in a suboptimal treatment response.

\section{References}

1. Koren G (2000) Nausea and Vomiting of Pregnancy: State of the art 2000. In: Bishai R 1: Motherisk.

2. Piwko C, Ungar WJ, Einarson TR, Wolpin J, Koren G (2007) The weekly cost of nausea and vomiting of pregnancy for women calling the Toronto Motherisk Program. Curr Med Res Opin 23: 833-40.

3. Niebyl JR (2010) Clinical practice. Nausea and vomiting in pregnancy. N Engl J Med 363: 1544-50.

4. Pasternak B, Svanström H, Hviid A (2013) Ondansetron in pregnancy and risk of adverse fetal outcomes. N Engl J Med 368: 814-23.

5. Clark SM, Costantine MM, Hankins GD (2012) Review of NVP and HG and Early Pharmacotherapeutic Intervention. Obstet Gynecol Int 2012: $252676-84$.

6. Rosenblatt A (2013) Time trends and risk factors for medication use during pregnancy, in Departments of Public Health. Ben-Gurion University of the Negev: Beer Sheva, Israel.

7. Matsui D (2012) Adherence with drug therapy in pregnancy. Obstet Gynecol Int 2012: 796590.

8. Mazzotta P, Magee LA, Maltepe C, Lifshitz A, Navioz Y, et al. (1999) The perception of teratogenic risk by women with nausea and vomiting of pregnancy. Reprod Toxicol 13: 313-9.

9. Ebrahimi N, Maltepe C, Bournissen FG, Koren G (2009) Nausea and vomiting of pregnancy:using the 24-hour Pregnancy-Unique Quantification of Emesis (PUQE-24) scale. J Obstet Gynaecol Can 31: 803-7.

10. Madjunkova S, Maltepe C, Koren G (2013) The Leading Concerns of American Women with Nausea and Vomiting of Pregnancy Calling Motherisk NVP Helpline. Obstet Gynecol Int 2013: 752980.

11. Osterberg L, Blaschke T (2005) Adherence to medication. N Engl J Med 353: 487-97.

12. Contreras-Yáñez I, Ponce De León S, Cabiedes J, Rull-Gabayet M, Pascual-Ramos V (2010) Inadequate therapy behavior is associated to disease flares in patients with rheumatoid arthritis who have achieved remission with disease-modifying antirheumatic drugs. Am J Med Sci 340: 282-90.

13. McDonnell PJ, Jacobs MR (2002) Hospital admissions resulting from preventable adverse drug reactions. Ann Pharmacother 36: 1331-6.

14. Senst BL, Achusim LE, Genest RP, Cosentino LA, Ford CC, et al. (2001) Practical approach to determining costs and frequency of adverse drug events in a health care network. Am J Health Syst Pharm 58: 1126-32.

15. Graziottin A, Gardner-Nix J, Stumpf M, Berliner MN (2011) Opioids: how to improve compliance and adherence. Pain Pract 11: 574-81.

16. Koren G, Clark S, Hankins GD, Caritis SN, Miodovnik M, et al. (2010) Effectiveness of delayed-release doxylamine and pyridoxine for nausea and vomiting of pregnancy: a randomized placebo controlled trial. Am J Obstet Gynecol 203: 571.e571-577.

17. Daw JR, Mintzes B, Law MR, Hanley GE, Morgan SG (2012) Prescription drug use in pregnancy: a retrospective, population-based study in British Columbia, Canada (2001-2006). Clin Ther 34: 239-49. 